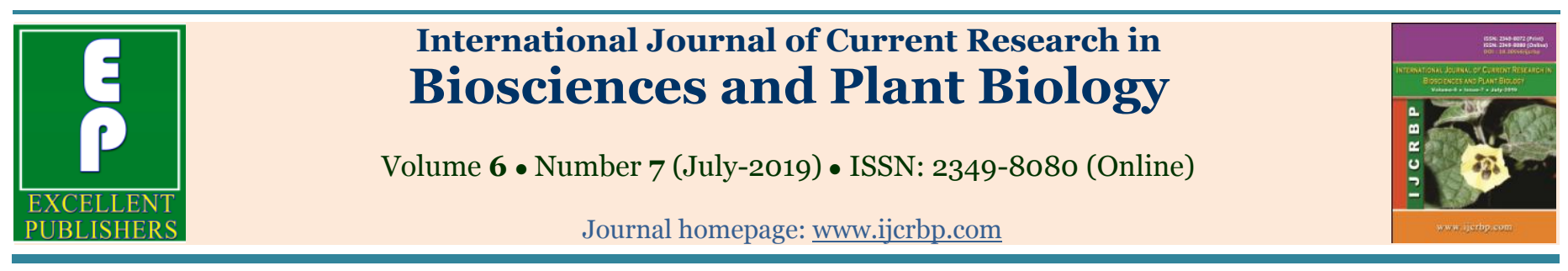

\title{
Protein tyrosine phosphorylation in buffalo spermatozoa cryopreserved in soya milk extender supplemented with taurine and trehalose
}

\author{
Haritima Batra1, Radhika Mohan ${ }^{2 *}$ and S.K. Atreja3
}

\begin{abstract}
${ }^{1}$ Senior Research Fellow, ABC division, ICAR-National Dairy Research Institute, Karnal, Haryana- 132 001, India ${ }^{2}$ Institute of Integrated \& Honors Studies (IIHS), Kurukshetra University, Kurukshetra- 136 119, Haryana, India 3Principal Scientist, ABC division, ICAR-National Dairy Research Institute, Karnal, Haryana- 132 o01, India
\end{abstract}

*Corresponding author; e-mail: radhika.mohanndri@gmail.com

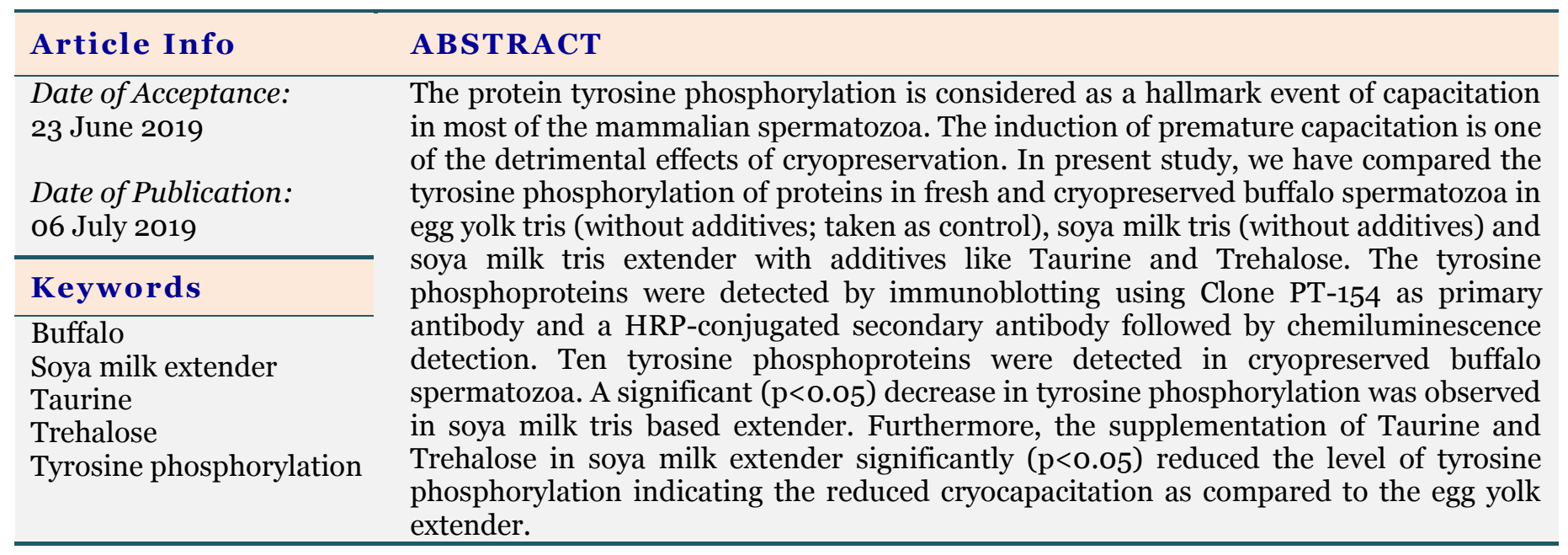

\section{Introduction}

Procedures that are employed to cryopreserve sperm i.e. dilution, cooling, freezing and thawing (Cormier et al. 2003) induce sub lethal damage due to sudden temperature changes, osmotic stress and intracellular ice crystal formation (Hammadeh et al., 2001) leading to premature capacitation called "Cryocapacitation" (Watson, 2000; Bailey et al., 2000). The biochemical changes that are associated with the cryocapacitation are an efflux of cholesterol that leads to an increase in membrane fluidity, bicarbonates, intracellular $\mathrm{pH}, \mathrm{Ca}^{+2}$ and cAMP dependent tyrosine phosphorylation (Baldi et al. 2000). Phosphorylation of proteins is a post translational modification event that acts as one of the regulatory mechanism to control various cellular processes (Hunter, 2000; Pawson, 2004). Various studies (Visconti et al., 1997, Galantino et al., 1997) have previously reported that capacitation is correlated with cAMP dependent increase in protein tyrosine phosphorylation in mammalian species. Protein tyrosine phosphorylation is also known to regulate sperm function such as motility and zona pellucida recognition (Shi and Roldan, 1995). 
An extender which is used to cryopreserve semen should contain energy source substrate, high molecular weight to prevent cold shock and ionic and non-ionic substances to maintain osmotic pressure and $\mathrm{pH}$ (Aires et al., 2003). A very high progesterone concentration in egg yolk extenders used for semen cryopreservation activates channels that result in uncontrolled calcium influx and premature capacitation as reported in a recent study (Dalal et al., 2019).

Nowadays, plant based extenders show competitive results and are used for cryopreservation because it prevents viral infections and allergic reactions that are mostly associated with egg yolk based extenders (Hinsch et al., 1997). In addition, cryoprotectants such as Taurine (a sulfonic amino acid) and Trehalose, (an alpha linked disaccharide) are supplemented to the extenders for freezing buffalo (Chen et al., 1993; Uysal et al., 2007), boar (Hu et al., 2009), ram (Bucak et al., 2007) and dog (Michael et al., 2007) spermatozoa also improve the sperm function after cryopreservation. Taurine act as an anti-oxidant and help in membrane stabilization (Meizel et al., 1980) whereas Trehalose has high water retention and prevents ice crystallization (Aboagla and Terada, 2003).

The objective of the present study was to investigate the status of protein tyrosine phosphorylation in buffalo spermatozoa cryopreserved in soya milk extender which has not been reported as yet. The effect of cryoprotectants such as Taurine and Trehalose in soya milk extender has also been studied.

\section{Materials and methods}

\section{Semen collection and cryopreservation}

The Murrah buffalo (Bubalis bubalis) bulls (3-5 years age) were maintained at Artificial Breeding Research Centre, NDRI, India, under uniform nutritional conditions. Semen was collected, twice a week, from four buffalo bulls (eight ejaculates from one bull) using artificial vagina (IMV, L'Aigle Cedex France) maintained at $41^{\circ} \mathrm{C}$. The semen was assessed immediately for mass activity and progressive motility by light microscopy and ejaculates were immersed in a warm water bath at $38.5^{\circ} \mathrm{C}$ until semen was extended. Standard semen characteristics like progressive motility, viability and membrane integrity in the fresh semen ejaculates were also studied. Semen ejaculates presenting more than $80 \%$ progressive motility and $1 \times 10^{9}$ cells / ml were used in this study. Each ejaculate was split into aliquots and one aliquot was diluted in tris based extender (20\% egg yolk v/v, $274 \mathrm{Mm}$ Tris , $87 \mathrm{~mm}$ Citric acid , $43 \mathrm{~mm}$ Glucose , 10 oo ooo IU Benzyl penicillin per litre, 750 ooo IU Streptomycin per litre) without additive and taken as control . Other aliquots were diluted in soya milk (25\% v/v replaced in Tris base extender, Mohan and Atreja, 2014) without additives and soya milk with additives viz. Taurine $(50 \mathrm{mM})$ or Trehalose $(100 \mathrm{mM})$. Diluted samples were aspirated into medium sized (0.25 ml) French straws, sealed with polyvinyl alcohol powder and equilibrated at $4^{\circ} \mathrm{C}$ for $4 \mathrm{~h}$. After equilibration, the straws were frozen in liquid nitrogen vapour, $5 \mathrm{~cm}$ above liquid nitrogen, for $10 \mathrm{~min}$ and then the straws were plunged into liquid nitrogen for storage. After storage for 4 weeks, frozen straws were thawed at $37^{\circ} \mathrm{C}$ for $30 \mathrm{~s}$ in a water bath and used for the study of different semen parameters.

\section{Sperm culture medium}

Modified Tyrode's Hepes - buffered medium (spTALPH) was used for washing of spermatozoa $(\mathrm{pH}$ 7.4-7.45, osmolarity: 280-285 mosmol $/ \mathrm{kg}$ ) and modified Tyrode's bicarbonate-buffered medium (sp- TALP, pH 7.40, osmolarity: 265-270 mosmol $/ \mathrm{kg}$ ) was used for sperm culture. Both the media were prepared as by Galantino-Homer et al. (1997).

\section{Semen processing}

Diluted frozen - thawed semen were collected separately into $15 \mathrm{ml}$ polypropylene tubes and centrifuged at $275 \times \mathrm{g}$ for $6 \mathrm{~min}$. The seminal plasma was discarded and pellet was subjected to two washes by resuspension with $3 \mathrm{ml}$ of sp- TALP and centrifugation at $275 \times \mathrm{g}$ for $5 \mathrm{~min}$. The loose sperm pellet was resuspended with $3 \mathrm{ml}$ of $\mathrm{sp}-$ TALP and subjected to a final centrifugation step to remove the $\mathrm{sp}$ - TALP media completely. The pellet was resuspended with sp - TALP and the sperm concentration was determined by haemocytometer and adjusted to $100 \times 10^{6}$ cells/ml with $\mathrm{sp}$ - TALP. 


\section{Post thaw sperm motility and viability}

For the post - thaw motility analysis, five cryopreserved semen straws were thawed by immersion in a water bath at $37^{\circ} \mathrm{C}$ for $30 \mathrm{~s}$. Immediately $10 \mu \mathrm{l}$ of thawed semen aliquots were transferred into glass slides and cover slips applied. Sperm motility was assessed by determining the percentage of spermatozoa showing any movement of the flagellum. The percentage of linear motile sperm was estimated at $37^{\circ} \mathrm{C}$ by light microscope at $400 x$. At least 300 spermatozoa were counted per slide. The mean of the three estimations was used as the final motility score (Mohan and Atreja, 2014). The sperm viability was assessed according to the method of Therien and Manjunath (2003) using eosin B and nigrosin stains. Briefly , $10 \mu \mathrm{l}$ of sperm suspension was incubated at $37^{\circ} \mathrm{C}$ for 2 min on a microscope slide and mixed with $5 \mu$ of $5 \%$ eosin B and $5 \mu \mathrm{l}$ of $10 \%$ nigrosin. The stained sperm were spread on the slide and 400 spermatozoa were counted for viable (white) and nonviable (red) cells under light microscope (400X).

\section{Hypoosmotic swelling test (HOST)}

The hypoosmotic swelling test (HOST) was used to evaluate the functional integrity of sperm plasma membrane. This test was performed by incubating $10 \mu \mathrm{l}$ of fresh semen with $990 \mu \mathrm{l}$ of $150 \mathrm{mOsmol} / \mathrm{kg}$ hypoosmotic solution $(74.98 \mathrm{mM}$ fructose, 24.99 $\mathrm{mM}$ trisodium citrate) and $100 \mu \mathrm{l}$ of cryopreserved semen with $900 \mu \mathrm{l}$ of $100 \mathrm{mOsM}$ hypoosmotic solution (49.95 mM fructose, $16.66 \mathrm{mM}$ trisodium citrate) at $38.5^{\circ} \mathrm{C}$ for $1 \mathrm{~h}$.

After incubation, a small drop from the fresh and cryopreserved semen suspension separately was placed on a clean, dry and grease free glass slide and covered with a cover slip. The slide was examined under the high power magnification (400X) of a bright field microscope. A minimum of 200 spermatozoa were counted per slide for different types of swelling pattern.

\section{Detection of tyrosine - phosphorylated proteins}

Sperm proteins were extracted according to the method of Galantino - Homer et al. (1997) using
$1 \mathrm{mM}$ sodium orthovanadate as tyrosine phosphatase inhibitor and total protein in the extract was analyzed by the method of Lowry et al. (1951).

\section{SDS PAGE and immunoblotting}

Ten microgram of cell lysate was loaded and proteins were resolved by SDS-PAGE on a $10 \%$ $(\mathrm{w} / \mathrm{v})$ uniform gel. Separated proteins were transferred to Immobilon-P PVDF membrane adopting a two- step transfer method of Otter et al. (1987). Equal loading and transfer efficiency was checked by staining the membrane with $0.5 \%$ ponceu S dye in 1\% glacial acetic acid (Salinovich and Montelaro, 1986) and by analysing the transfer of pre-stained molecular weight marker onto the PVDF membrane. The membrane was then blocked with $5 \%(\mathrm{w} / \mathrm{v})$ non-fat dried milk prepared in Tris-buffered saline with Tween -20 and sodium orthovandate (TBS-TV: $20 \mathrm{mM}$ tris, $150 \mathrm{mM}$ NaCL, pH 7.6; 0.1\%(v/v) Tween 20, 1mM $\mathrm{Na}_{3} \mathrm{VO}_{4}$ ) for overnight at $4^{\circ} \mathrm{C}$. The membrane was incubated with monoclonal antiphosphotyrosine antibody [Sigma: 1869, Clone pT- 154, diluted (1:2000) in TBSTV] for $2 \mathrm{~h}$ at room temperature. After washing with TBS-T, membrane was incubated with goat anti-mouse IgG- Peroxidase activity was visualized by Immobilon Western blotting chemiluminescent detection reagents (Millipore Corporation , Billerica, MA 01821 U.S.A) according to manufacturer's instruction using Kodak X-OMAT-AR X- ray films. Duplicate blots were also probed with secondary antibody alone to rule out any non- specific binding to transferred proteins. After chemiluminescence detection, the $\mathrm{X}$ - ray films were photographed by an image analysis (Image Scanner III, GE- Healthcare) and densitometric analysis was performed with Multi Gauge analysis software (Version 2.2. Fujifilm, Tokyo, Japan). To determine the relative changes in the intensities of protein bands, the intensity obtained with the control spermatozoa was assigned base value of 100.

\section{Statistical analysis}

All the experiments were done in three replicates. Data were analysed of variance using the statistical product and service solutions, version 17.0.1 software (SPSS Inc.,Chicago IL, USA). 


\section{Results}

\section{Sperm motility, viability and membrane integrity}

The standard semen quality parameters like progressive motility, viability, membrane integrity (HOST) of fresh and cryopreserved (post thaw) spermatozoa were assessed and results are shown in Fig. 1. Cryopreservation of semen significantly reduced $(\mathrm{p}<0.05)$ the motility of spermatozoa $(46.66 \pm 1.66)$ as compared to fresh coordinates $(81.66 \pm 1.66)$. The viability of the cryopreserved spermatozoa was significantly declined $(\mathrm{p}<0.05)$ due to freeze thaw procedures. The percentage of spermatozoa with coiled tails (membrane intact) was also significantly $(\mathrm{p}<0.05)$ reduced in cryopreserved semen $(39.33 \pm 1.45)$ as compared to the fresh semen $(76.66 \pm 4.33)$. The comparison between extenders showed no significant difference in terms of sperm motility, viability and membrane integrity $(\mathrm{p}<0.05)$. The post thaw motility of spermatozoa extended in soya milk extender was $(48.33 \pm 1.66)$ as compared to control group $(46.66 \pm 1.66)$.

The viability of spermatozoa extended in soya milk extender was $(71 \pm 1.73)$ as compared to control group $(68 \pm 2.08)$ which is almost same. The percentage of spermatozoa extended in soya milk extender with coiled tails $(40.66 \pm 0.88)$ was almost similar in control group $(39.33 \pm 1.45)$. The addition of cryoprotectant like taurine and trehalose to the freezing extender led to higher post-thaw motility $(51.66 \pm 1.66 ; 50 \pm 2.88)$ as compared to control group (46.66 \pm 1.66 ; $\mathrm{p}<$ 0.05). Significant differences were observed in viability $(67.66 \pm 2.90,69 \pm 2)$ and HOST (45 \pm $2,46.33 \pm 4.05)$ upon addition of additives to extender during freeze-thawing process compared to control group $(\mathrm{p}<0.05)$ (Fig . 1).

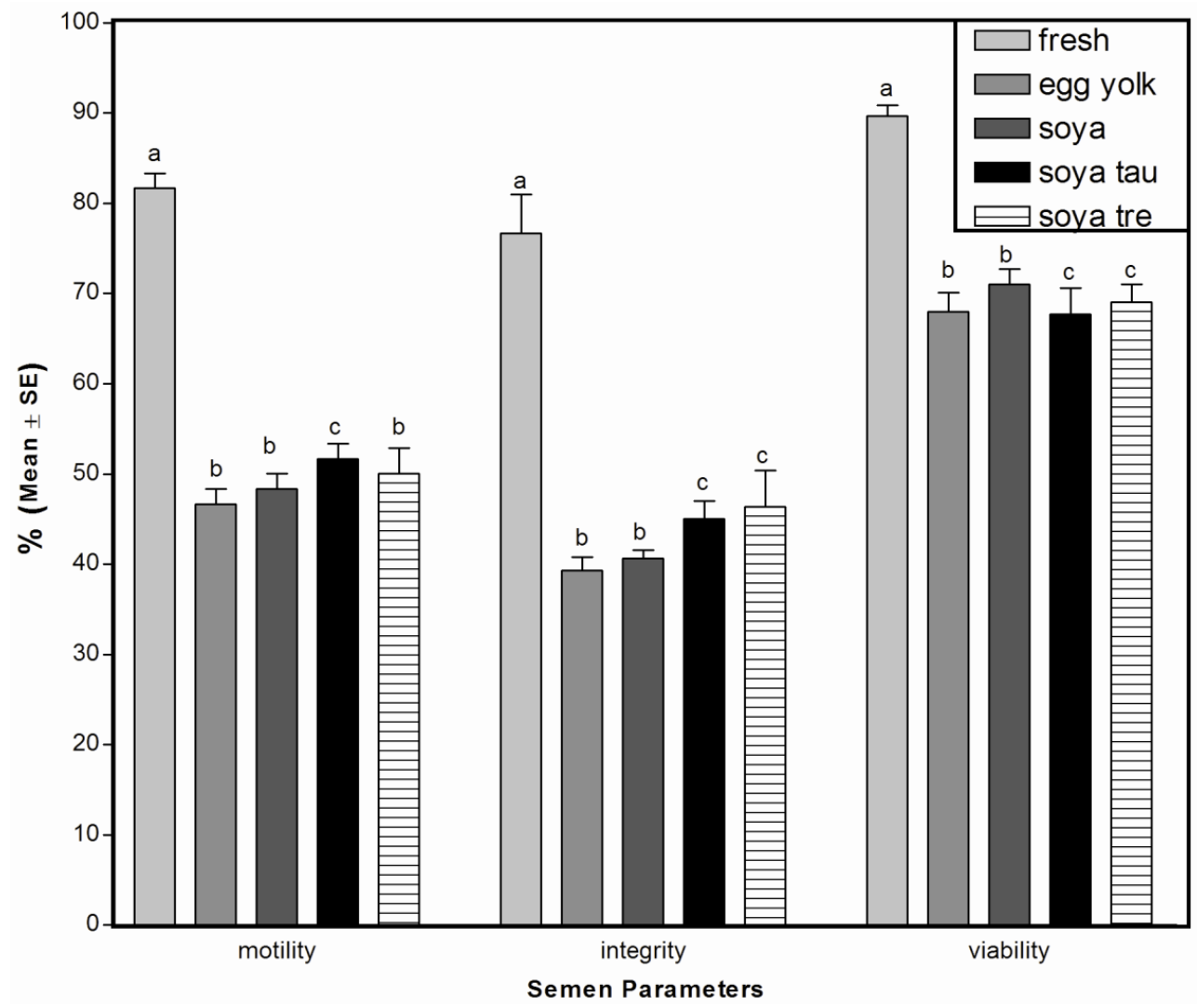

Fig. 1: Sperm motility, Viability and membrane integrity of buffalo spermatozoa diluted in Egg yolk Extender and Soya milk Extender and presence of additives viz. Taurine and Trehalose in soya milk extender. Values are the mean \pm S.E.M. of three experiments. Mean with different letters $a, b, c$ are significantly different $(\mathrm{p}<0.05)$. 


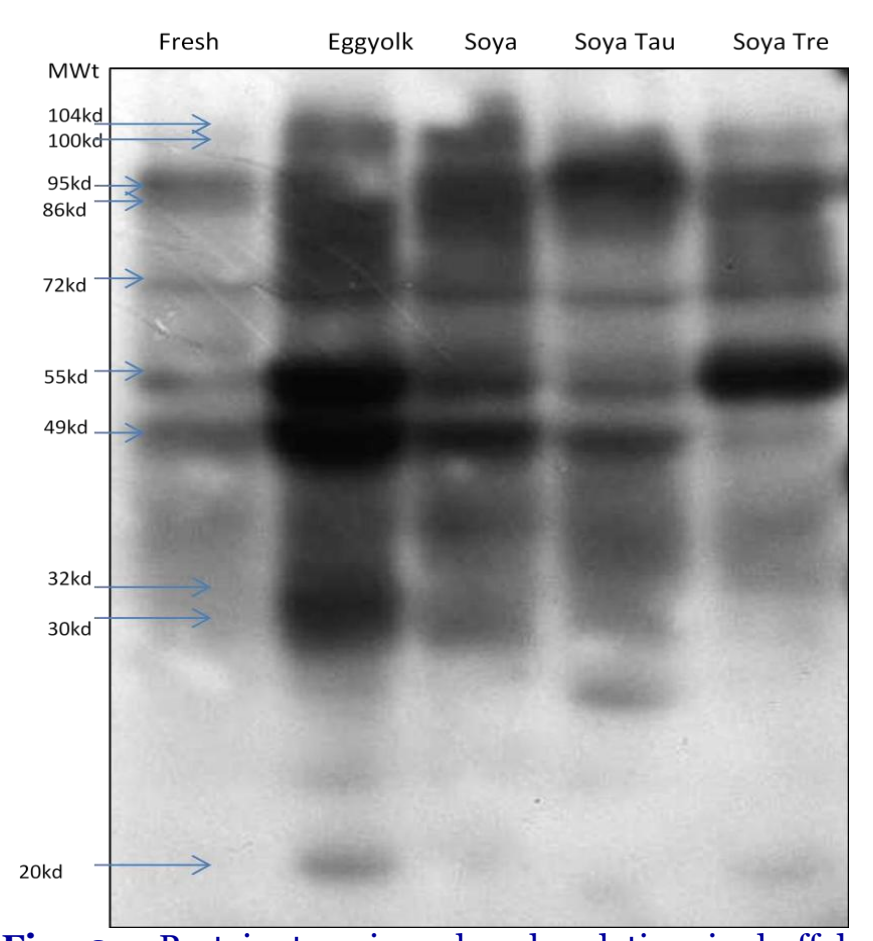

Fig. 2: Protein tyrosine phosphorylation in buffalo spermatozoa cryopreserved in egg yolk tris and soya milk tris extender (Soya milk tris extender with additives taurine and trehalose). The cryopreserved semen were thawed, processed and total proteins were extracted and resolved in 10\% uniform SDS-PAGE

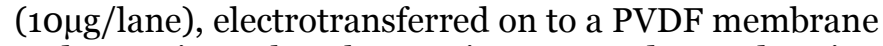
and tyrosine phosphoproteins were detected using monoclonal anti-phosphotyrosine antibody (clone pt154). The blot indicates following lanes: Lane 1) Fresh Buffalo spermatozoa - Fresh; Lane 2) Buffalo spermatozoa in Egg yolk Extender - Egg Yolk; Lane 3) Buffalo spermatozoa in soya milk extender - Soya; Lane 4) Buffalo spermatozoa + taurine in soya milk extender
- Soya Tau; Lane 5) Buffalo spermatozoa + trehalose in soya milk extender - Soya Tre.

\section{Detection of tyrosine phosphorylated proteins}

Tyrosine phosphorylation was estimated in both fresh and cryopreserved (with additives) buffalo spermatozoa (Fig. 2). Five tyrosine phosphorylated proteins $(49,55,72,86$ and 95 $\mathrm{kDa}$ designated as p49, p55, p72, p86 and p95) were detected in fresh buffalo spermatozoa.

Cryopreservation procedures significantly $(p<0.05)$ increased the tyrosine phosphorylation of proteins extensively and at least 10 proteins (20, 30, 32, 49, 55,72, 86, 95, 100 and $104 \mathrm{kDa})$ designated as p2O, p3o, p32, p49, p55, p72, p86, p95,p100 and p104 were found in buffalo spermatozoa cryopreserved in egg yolk extender as shown in Fig. 2. Similar tyrosine phosphoprotein profile was observed in buffalo spermatozoa cryopreserved in soya milk as well as soya milk supplemented with additives taurine and trehalose. However, the band densities for tyrosine phosphoproteins were less intensive in soya milk as well as soya milk supplemented samples as compared to egg yolk extender as shown in Table 1. Densitometric analysis revealed the relative band intensities (Table 1) of ten tyrosine phosphoproteins and statistically significant $(p<0.05)$ inhibition of tyrosine phosphorylation was found in soya milk extender (and with additives).

Table 1. Relative band intensities of protein tyrosine phosphorylated detected in cryopreserved buffalo (Bubalus bubalis) spermatozoa. Tyrosine phosphorylation in egg yolk extender without additives was taken as 100\%. Egg yolk extender was taken as control. Values are expressed as mean \pm S.E. of three replicates.

\begin{tabular}{|c|c|c|c|c|c|}
\hline $\begin{array}{l}\text { Molecular mass of the } \\
\text { detected tyrosine } \\
\text { phosphorylated } \\
\text { proteins (pkDa) }\end{array}$ & $\begin{array}{l}\text { Fresh } \\
\text { spermatozoa }\end{array}$ & $\begin{array}{l}\text { Spermatozoa } \\
\text { cryopreserved } \\
\text { in Tris based } \\
\text { egg yolk (EYC) } \\
\text { extender }\end{array}$ & $\begin{array}{l}\text { Spermatozoa } \\
\text { cryopreserved } \\
\text { in soya milk } \\
\text { extender }\end{array}$ & $\begin{array}{l}\text { Spermatozoa } \\
\text { cryopreserved } \\
\text { in soya milk } \\
\text { extender }+50 \\
\text { mM taurine }\end{array}$ & $\begin{array}{l}\text { Spermatozoa } \\
\text { cryopreserved in } \\
\text { soya milk } \\
\text { extender } \\
+ \text { 1oomM } \\
\text { trehalose } \\
\end{array}$ \\
\hline p104 & - & 100 & $93.21 \pm 0.32$ & $68.94 \pm .081$ & $63.15 \pm .56$ \\
\hline p100 & - & 100 & $105.26 \pm 0.26$ & $99.90 \pm 0.25$ & $77.34 \pm 0.45$ \\
\hline p95 & $98.45 \pm 0.30$ & 100 & $106.33 \pm 0.38$ & $114.98 \pm 0.44$ & $98.08 \pm 0.11$ \\
\hline p86 & $83.93 \pm 0.11$ & 100 & $104.28 \pm 0.27$ & $98.93 \pm 0.12$ & $95.70 \pm 0.45$ \\
\hline p72 & $64.47 \pm 0.33$ & 100 & $93.90 \pm 0.33$ & $76.06 \pm 0.47$ & $81.11 \pm 0.14$ \\
\hline p55 & $72.67 \pm 0.26$ & 100 & $85 \cdot 31 \pm 0.40$ & $71.46 \pm 0.32$ & $95.26 \pm 0.32$ \\
\hline p49 & $80.98 \pm 0.25$ & 100 & $91.22 \pm 0.52$ & $81.00 \pm 0.31$ & $53.11 \pm 0.11$ \\
\hline p32 & - & 100 & $71.45 \pm 0.31$ & $63.39 \pm 0.31$ & $45.53 \pm 0.43$ \\
\hline p3o & - & 100 & $74.99 \pm 0.50$ & $58.02 \pm 0.07$ & $37.47 \pm 0.67$ \\
\hline $\mathrm{p} 20$ & - & 100 & $54.10 \pm 0.21$ & $47.22 \pm 0.55$ & $67.98 \pm 0.49$ \\
\hline
\end{tabular}




\section{Discussion}

The increased global concern for semen contamination, control of pathogen transmission and microbial safety has replaced the traditional extenders with the choice of plant based chemically defined mediums in assisted reproductive technology. Egg yolk extenders increase the risk of production of endotoxins which may reduce the fertilizing capacity of spermatozoa (Aires et al., 2003). On the other hand, soya milk extender is free from such contamination and has better protection in comparison to egg yolk extender (Mohan and Atreja, 2014). The supplemented cryoprotectants in extenders protects the spermatozoa against freeze damage, maintain osmotic pressure and helps in stabilizing the membrane structure during freezing and thawing (Reddy et al., 2010). Several reports have widely studied the addition of Taurine and Trehalose to freezing extenders in order to improve sperm quality parameters (Bucak et al., 2007; Hu et al., 2009). In present study, buffalo spermatozoa extended in egg yolk, soya milk and additives in soya milk such as Taurine and Trehalose have been compared for various sperm quality parameters and protein tyrosine phosphorylation. Various reports have shown a time dependent increase in protein tyrosine phosphorylation of specific proteins of molecular range $40-120 \mathrm{kDa}$ in species like hamster (Kulanand and Shivaji, 2001), pigs (Tardif et al., 2001) and equine (Pommer et al., 2003). It is evident from these studies that protein tyrosine phosphorylation is an important post translational modification and it acts as one of the sperm cell's regulatory mechanism which is associated with capacitation. Our results are also in agreement to these studies and show a significant decrease $(\mathrm{p}<0.05)$ in post thaw motility, viability, membrane integrity and an increase in the degree of cryocapacitation in frozen-thawed buffalo spermatozoa as compared to fresh semen.

Soya milk contains lecithins which take care of plasma membranes and protect the viability of cells (Layek et al., 2016). In present study, the degree of cryocapacitation was significantly $(\mathrm{p}<0.05)$ less in spermatozoa cryopreserved in soya milk extender. Furthermore, addition of Taurine (50mM) and Trehalose (100mM) to soya milk extender also showed a significant reduction in pre-mature capacitation like changes as indicated by tyrosine phosphorylation in comparison to control samples. Taurine is a permeating cryoprotectant which causes membrane rearrangement resulting in better survival of spermatozoa during cryopreservation (Holt, 2000). On other hand, trehalose is a nonpermeating cryoprotectant that protects against the osmotic stress (Molinia et al., 1994). The findings in this study clearly indicate the use of soya milk extender with additives (Taurine and Trehalose) maintain the better condition of sperm viability, integrity, progressive motility and reduced tyrosine phosphorylation. Hence, cryocapacitation reduces in soya milk extenders with cryoprotectants in terms of reduced tyrosine phosphorylation.

\section{Acknowledgement}

The authors sincerely thank of Artificial Breeding Research Centre (ABRC), ICAR-NDRI, Karnal for providing assistance in collecting semen samples.

\section{Conflict of interest statement}

Authors declare that they have no conflict of interest.

\section{References}

Aboagla, E.M., Terada, T., 2003. Trehaloseenhanced fluidity of the goat sperm membrane and its protection during freezing. Biol. Reprod. 69,1245-1250.

Aires, J.M., Hinsch, K.D., Mueller-Schloesser, F., Bogner, K., Mueller Schloesser, S., Hinsch, E., 2003. In vitro and in vivo comparison of egg yolk-based and soybean lecithin-based extenders for cryopreservation of bovine semen. Theriogenology. 60, 269-279.

Bailey, J. L., Bilodeau, J. F., Cormier, N., 2000. Semen cryopreservation in domestic animals ; a damaging and capacitating phenomenon. J. Androl. 21, 1-7.

Baldi, E., Luconi, M. , Bonaccorsi, L., Muratori, M. Forti, G., 2000. Intracellular events and signalling pathways involved in sperm acquisition of fertilizing capacity and acrosome reaction. Front. Biosci. 1,5:E, 110-123.

Bucak, M.N., Atessahin, A., Varish, O., Yuce, A., Tekin, N.,Akcay, A., 2007. The influence of 
trehalose, taurine, cysteamine and hyaluronan on ram semen: microscopic and oxidative stress parameters after the freeze thawing process. Theriogenology. 67, 1060-1067.

Chen, Y., Foote, R.H., Brockett, C.C., 1993. Effect of sucrose, trehalose, hypotaurine, taurine, and blood serum on survival of frozen bull Sperm. Cryobiology. 30, 423-431.

Cormier, N., Bailey, J. L., 2003. A differential mechanism is involved during heparin- and cryopreservation-induced capacitation of bovine spermatozoa. Biol. Reprod. 69, 177-185.

Dalal, J., Kumar, P., Chandolia, R.K., Pawaria, S., Rajendran R, Sheoran, S., Andonissamy, J., Kumar, D., 2019. A new role for RU486 (mifepristone): it protects sperm from premature capacitation during cryopreservation in buffalo. Scientific Reports 9, Article number 6712.

Galantino-Homer, H.L., Visconti, P.E., Kopf, G.S., 1997. Regulation of protein tyrosine phosphorylation during bovine sperm capacitation by a cyclic adenosine 3', 5'monophosphate-dependent pathway. Biol. Reprod. 56, 707-719.

Hammadeh, M.E., Szarvasy, D., Zeginiadou, T., Rosenbaum, P., Georg, T., Schmidt, W., 2001. Evaluation of Cryoinjury of Spermatozoa After Slow (Programmed Biological Freezer) or Rapid (Liquid Nitrogen Vapour) FreezeThawing Techniques. J. of Assis. Reprod. Gen.18, 7 .

Hinsch, E., Hinsch, K.D., Boehm, J.G., Schill, W.B., Mueller-Schloesser, F.,1997,. Functional parameters and fertilization success of bovine semen cryopreserved in egg yolk-containing extenders. Reprod. Dom. Anim. 32,143-149.

Holt, W.V. ,200o. Fundamental aspects of sperm cryobiology: the importance of species and individual differences. Theriogenology. 53,4758.

Hu, J.H., Li, Q.W., Li, G., Jiang, Z.L., Bu, S.H., Yang, H.,Wang, L.Q., 2009. The cryoprotective effect of trealose supplementation on boar spermatozoa quality. Anim. Reprod. Sci. 112, 107-118.

Hunter, T., 2000. Signaling-2000 and beyond. Cell.100, 113-127.

Kulanand, J., Shivaji, S., 2001. Capacitationassociated changes in protein tyrosine phosphorylation, hyperactivation and acrosome reaction in hamster spermatozoa.
Andrologia. 33, 95-104.

Layek, S.S., Mohanty, T.K., Kumaresan, A., Parks, J.E.,2016. Cryopreservation of bull semen: Evolution from egg yolk based to soyabean based extenders. Anim.Reprod. Sci. 172,1-9.

Lowry, O.H., Rosebrough, N.J., Farr, A.L., Randall, R.J., 1951. Protein measurement with the folin phenol reagent. J. Biol. Chem, 193, 265-275.

Meizel, S., Lui, C.W., Working, P.K., Mrsny, R.J., 1980. Taurine and hypotaurine: their effect on motility, capacitation and the acrosome reaction of hamster sperm in vitro and their presence in sperm and reproductive tract fluids of several mammals. Dev. Gro. Differen. 22,483-494.

Michael, A., Alexopoulos, C., Pontiki, E., Hadjipavlou-Litina, D., Saratsis, P., Boscos, C., 2007. Effect of anti-oxidant supplementation on semen quality and reactive oxygen species of frozen -thawed canine spermatozoa. Theriogenology. 68, 204-212.

Mohan, R., Atreja, S.K., 2014. Soya milk tris-based phytoextender reduces apoptosis in cryopreserved Buffalo (Bubalus bubalis) spermatozoa. Reprod. Dom. Anim. 49, 797805.

Molinia, F.C., Evans, G., Casares, P.I., Maxwell, W.M.C.. 1994. Effect of monosaccharides and disaccharides in tris-based diluents on motility, acrosome integrity and fertility of pellet frozen ram spermatozoa. Anim. Reprod. Sci. 36, 113122.

Otter, T., King, S.M., Witman, G.B., 1987. A two step procedure for efficient transfer of both high-molecular weight (greater than 400,000) and low molecular weight (less than 20,000) proteins. Anal. Biochem. 162, 370-377.

Pawson, T., 2004. Specificity in signal transduction: from phosphotyrosine-SH2 domain interactions to complex cellular systems. Cell. 116, 191-203.

Pommer, A.C., Rultllant, J., Meyers, S.A., 2003. Phosphorylation of protein tyrosine resiudes in fresh and cryopreserved stallion spermatozoa under capacitating conditions. Biol. Reprod, 68, 1208-1214.

Reddy, N.N.S., Gali, J.M., Atreja, S.K., 2010. Effect of adding taurine and trehalose to a tris-based egg yolk extender on buffalo (Bubalus bubalis) sperm quality following cryopreservation. Anim. Reprod. Sci. 119, 183-190.

Salinovich, O., Montelaro, R.C., 1986. Reversible 
staining and peptide mapping of proteins transferred to nitrocellulose after separation by sodium dodecyl sulfate polyacrylamide gel electrophoresis. Anal. Biochem. 156, 341-347.

Shi, Q, Roldan, E., 1995. Bicarbonate/CO2 is not required for zona pellucid or progesteroneinduced acrosomal exocytosis of mouse spermatozoa but is essential for capacitation. Biol. Reprod. 52, 540-546.

Tardif, S., Dube, C., Chevalier, S., Bailey, J.L., 2001. Capacitation is associated with tyrosine phosphorylation and tyrosine kinase -like activity of pig sperm proteins. Biol. Reprod. 65, 784-792.

Therien, I., Manjunath, P., 2003. Effect of progesterone on bovine sperm capacitation and acrosome reaction. Biol. Reprod. 69,1408-1415.

Uysal, O., Bucak, M.N., Yavas, I. ,Varisl, O., 2007. Effect of various antioxidants on the quality of frozen-thawed bull semen. J. Anim. Vet. Adv. 6, 1362-1366.

Visconti, P.E., Steward-Savage, J., Blasco, A., Battaglia, L., Miranda, P., Kopf, G.S. Tezon, J.G., 1997. Roles of bicarbonate, cAMP and protein tyrosine phosphorylation on capacitation and the spontaneous acrosome reaction of hamster sperm. Biol. Reprod. 61, 76-84.

Watson, P.F., 2000. The causes of reduced fertility with cryopreserved semen. Anim. Reprod. Sci., 60-61, 481-492.

\section{How to cite this article:}

Batra, H., Mohan, R., Atreja, S.K., 2019. Protein tyrosine phosphorylation in buffalo spermatozoa cryopreserved in soya milk extender supplemented with taurine and trehalose. Int. J. Curr. Res. Biosci. Plant Biol. 6(7), 18-25. doi: https://doi.org/10.20546/ijcrbp.2019.607.003 